\title{
ANALISIS SIKAP, PENGETAHUAN, KETERSEDIAAN BUAH DAN SAYUR DENGAN KONSUMSI BUAH, SAYUR DAN STATUS GIZI PADA SISWA SEKOLAH MENENGAH ATAS DI PALEMBANG
}

\author{
ANALYZE OF ATTITUDES, KNOWLEDGE, AVAILABILITY OF FRUITS AND \\ VEGETABLES WITH CONSUMPTION OF FRUITS, VEGETABLES BODY MASS \\ INDEX AT SENIOR HIGH SCHOOL STUDENTS IN PALEMBANG
}

\author{
Eliza \\ Jurusan Gizi, Politeknik Kementrian Kesehatan Palembang, Sumatera Selatan, Indonesia \\ (email penulis korespodensi: eliza_limar@yahoo.co.id)
}

Info Artikel: Diterima: 30 April $2019 \quad$ Revisi: 21 Mei $2019 \quad$ Diterima: 31 Mei 2019

\begin{abstract}
ABSTRAK
Latar belakang: Manfaat konsumsi buah dan sayur telah terbukti menguntungkan kesehatan, akan tetapi sebagian besar penduduk Indonesia memiliki tingkat konsumsi buah dan sayur sangat rendah. Tujuan penelitian adalah mengetahui hubungan antara sikap, pengetahuan, ketersedian buah dan sayur dengan status gizi siswa SMA Xaverius 2 Palembang.

Metode: Jenis penelitian bersifat observasional analitik dengan rancangan penelitian potong lintan (cross-sectional). Sampel diambil menggunakan teknik proporsional stratified random sampling sebanyak 60 responden. Pengumpulan data konsumsi buah dan sayur menggunakan recall dan $F F Q$ form, data sikap, pengetahuan, ketersediaan buah dan sayur menggunakan kuesioner. Data status gizi menggunakan Indeks Massa Tubuh (IMT). Data diolah dengan menggunakan uji chi-square.

Hasil: Hasil penelitian menunjukkan bahwa sebesar 63,3\% konsumsi buah dan sayur siswa SMA Xaverius 2 adalah kurang dan konsumsi buah dan sayur berhubugan dengan sikap (pv=0,0005), pengetahuan $(\mathrm{pv}=0,001)$ dan ketersediaan buah dan sayur $(0,038)$.

Kesimpulan : Konsumsi buah berhubungan dengan sikap, pengetahuan, ketersediaan buah dan sayur di rumah dengan konsumsi buah dan sayur siswa SMA Xaverius 2 Palembang $(\mathrm{p}<0,05)$. Ada hubungan yang signifikan antara konsumsi buah dan sayur dengan status gizi siswa SMA Xaverius 2 Palembang $(\mathrm{p}<0,05)$.
\end{abstract}

Kata Kunci : Sikap, pengetahuan, buah dan sayur, status gizi, remaja

\section{ABSTRACT}

Background: The benefits of fruit and vegetable consumption have proven to be beneficial to health, but the majority of Indonesia's population has a very low. The purpose of this study was to determine the relationship between attitudes, knowledge, availability of fruits and vegetables with the nutritional status of Xaverius 2 Palembang high school students.

Methods: This research was analytic observational with cross-sectional study design. The study population was all Xaverius 2 Palembang high school students taken using the Proportional Stratified Random Sampling Technique. The research sample consisted of 60 people. Data collection of fruit and vegetable consumption using recall and FFQ forms, attitude, knowledge, fruit and vegetable availability using a questionnaire. Nutritional status used Body Mass Index (BMI). Data were processed using chi-square test.

Results: showed that $63.3 \%$ of Xaverius 2 Senior High School students' fruit and vegetable consumption was lacking. There were an assossiaciotion among attitude, knowledge, and availability of fruits and vegetables at home with fruit and vegetable consumption of Xaverius 2 Palembang high school students.

Conclusion:There were a significant relationship between attitude, knowledge, and availability of fruits and vegetables at home with fruit and vegetable consumption of Xaverius 2 Palembang high school students. There was a significant relationship between fruit and vegetable consumption with the nutritional status of Xaverius 2 Palembang high school students.

Keywords: attitude, knowledge, consumption of fruits and vegetables, Body Mass Index 


\section{PENDAHULUAN}

Salah satu pesan dari Gerakan Masyarakat Hidup Sehat (GERMAS) yang dicanangkan oleh Presiden RI adalah konsumsi buah dan sayur. Manfaat konsumsi buah dan sayur telah terbukti menguntungkan kesehatan, akan tetapi sebagian besar penduduk Indonesia memiliki tingkat konsumsi buah dan sayur sangat rendah yaitu sebesar 93.6\%. ${ }^{1}$ Peranan buah dan sayur dalam menurunkan risiko penyakit berhubungan dengan zat gizi yang dikandungnya seperti vitamin, kalium, serat, antioksidan, folat, flavonoid dan senyawa fitokimia lainnya. ${ }^{2}$

Konsumsi buah dan sayur dipengaruhi oleh tiga faktor utama, yaitu sosio demografi, individu dan lingkungan. ${ }^{3,4}$ Ketersediaan dan akses pangan merupakan faktor lingkungan yang mempengaruhi konsumsi buah dan sayur. 5, Lingkungan yang berhubungan dengan makanan yang diciptakan orangtua di rumah membentuk pola penerimaan makanan dan asupan pangan anak. ${ }^{7}$ Paparan yang sering dan pengenalan rasa

\section{METODE}

Jenis penelitian bersifat observasional analitik dengan rancangan penelitian crosssectional. Populasi penelitian adalah semua siswa kelas X dan XI SMA Xaverius 2 Palembang. Metode pengambilan sampel menggunakan Proporsional Stratified Random Sampling. Kriteria inklusi: semua siswa kelas X dan XI yang berusia 14-17 tahun, bisa diajak berkomunikasi, dalam keadaan sehat dan bersedia ikut dalam penelitian. Penentuan jumlah sampel berdasarkan rumus yang ditemukan oleh Lemeshow (1997), jumlah sampel sebanyak 60 orang.

\section{HASIL}

Hasil analisis univariat disajikan dalam bentuk tabel distribusi karakteristik responden dan konsumsi buah dapat dilihat pada Tabel 1 dan Tabel 2. Tabel 1 menunjukkan bahwa siswa SMA Xaverius 2 Palembang yang menjadi responden dalam penelitian ini terdiri dari 32 orang $(53,3 \%)$ adalah laki-laki dan 28 orang $(46,7 \%)$ adalah perempuan. Usia siswa SMA Xaverius 2 Palembang yang paling banyak berusia 16 tahun yaitu sebesar 30 orang $(50 \%)$, hanya 2 orang $(3,3 \%)$ yang berusia 17 tahun. sayuran pada anak usia 2-3 tahun merupakan strategi yang baik untuk mengubah penerimaan sayuran yang baru dikenal. ${ }^{8}$

Berdasarkan data Riskesdas tahun 2013, pada umur $\geq 10$ tahun yang kurang mengkonsumsi buah dan sayur sebesar 93.5\%. Data Riset Kesehatan Dasar di Sumatera selatan tahun 2007 yang kurang mengkonsumsi buah dan sayur didapatkan data sebesar 97.0\%, dan tingkat wilayah Kota Palembang sebesar $96.1 \% .^{9}$

Konsumsi buah dan sayur pada remaja termasuk rendah, hal ini dikarenakan bahwa buah dan sayur bukan merupakan makanan prestige dibandingkan makanan fast food yang sedang tren di kalangan remaja saat ini, hal tersebut berdampak pada konsumsi buah dan sayur remaja berkurang. ${ }^{10}$ Penelitian ini bertujuan untuk menganalisis sikap, pengetahuan, ketersediaan buah dan sayur dengan konsumsi buah dan sayur serta status gizi siswa SMA Xaverius 2 Palembang.

Pengumpulan data dibagi menjadi dua yaitu data primer dan data sekunder. Data primer yang diperoleh dengan menggunakan metode observasi langsung dengan menggunakan kuesioner yang berisi sikap, pengetahuan, dan ketersediaan buah dan sayur di rumah. data konsumsi buah dan sayur menggunakan form recall dan $F F Q$. Indikator status gizi yang digunakan adalah Indeks Massa Tubuh (IMT) diperolah dengan melakukan penimbangan berat badan dan pengukuran tinggi badan. Analisis data melalui analisis univariat dan bivariat menggunakan uji chi-square.

Konsumsi buah dan sayur siswa SMA Xaverius 2 Palembang dapat dilihat pada tabel 2. Konsumsi buah dan sayur dikategorikan kurang jika konsumsi buah dan sayur < 400 gram/hari. Konsumsi buah dan sayur dikategorikan baik jika konsumsi buah dan sayur $\geq 400$ gram/hari.

Sebagian besar siswa SMA 2 Xaverius Palembang konsumsi buah dan sayurnya kurang yaitu sebanyak 38 orang $(63,3 \%)$ sedangkan yang konsumsi buah dan sayur yang baik sebanyak 22 orang $(36,7 \%)$. 
Tabel 1. Distribusi Karakteristik Siswa Xaverius 2 Palembang

\begin{tabular}{lcc}
\hline Karakteristik responden & n & $\begin{array}{c}\text { Persentase } \\
(\mathbf{\%})\end{array}$ \\
\hline Jenis kelamin & 32 & 53,3 \\
1. Laki-laki & 28 & 46,7 \\
2. Perempuan & & \\
Umur & 6 & 10,0 \\
1. 14 tahun & 22 & 36,7 \\
2. 15 tahun & 30 & 50,0 \\
3. 16 tahun & 2 & 3,3 \\
4. 17 tahun & & \\
Konsumsi buah dan sayur & 38 & 63,3 \\
1. Kurang & 22 & 36,7 \\
2. Baik & & \\
\hline
\end{tabular}

Faktor-faktor yang mempengaruhi konsumsi buah dan sayur yang dianalisis pada penelitian ini terdiri dari sikap, pengetahuan, ketersediaan buah dan sayur di rumah, siswa
SMA Xaverius 2 Palembang.

Distribusi faktor-faktor yang mempengaruhi konsumsi buah dan sayur responden dapat dilihat pada Tabel 2.

Tabel 2. Distribusi Faktor-faktor yang Mempengaruhi Konsumsi Buah dan Sayur Siswa SMA Xaverius 2 Palembang

\begin{tabular}{lcc}
\hline Variabel & n & \% \\
\hline Sikap & 28 & 46,7 \\
1. Kurang baik & 32 & 53,3 \\
2. Baik & & \\
Pengetahuan & 31 & 51,7 \\
1. Kurang baik & 29 & 48,3 \\
2. Baik & & \\
Ketersediaan Buah dan Sayur di Rumah & 21 & 35,0 \\
1. Kurang baik & 39 & 65,0 \\
2. Baik & & \\
Indeks Masa Tubuh & 2 & 3,3 \\
1. Kurang & 43 & 71,7 \\
2. Normal & 15 & 25,0 \\
\hline
\end{tabular}

Berdasarkan Tabel 2 dapat dilihat bahwa sebanyak 32 orang $(53,3 \%)$ mempunyai sikap yang baik terhadap buah dan sayur. Ada 31 orang $(51,7 \%)$ mempunyai pengetahuan yang kurang baik. Sebanyak 39 orang $(65,0 \%)$ siswa SMA Xaverius 2 Palembang yang menyatakan ketersediaan buah dan sayur di rumah baik. Sebanyak 43 orang $(71,7 \%)$ siswa SMA Xaverius 2 Palembang status gizinya normal. Sikap pada penelitian ini adalah pernyataan sikap dan pandangan siswa SMA Xaverius 2 Palembang terhadap buah dan sayur yang dinilai dari kuesioner. Berdasarkan Tabel 3 menunjukkan bahwa sikap siswa yang kurang baik dan konsumsi buah dan sayur yang kurang sebesar $89,3 \%$. Hasil uji statistik menunjukkan bahwa ada hubungan yang signifikan antara sikap dengan konsumsi buah dan sayur $(\mathrm{p}=$ $0,0005)$. 
Tabel 3. Hubungan antara Sikap, Pengetahuan dan Ketersediaan Buah dan Sayur dengan Konsumsi Buah dan Sayur Siswa SMA Xaverius 2 Palembang

\begin{tabular}{|c|c|c|c|c|c|c|c|}
\hline \multirow{3}{*}{ Variabel } & \multicolumn{4}{|c|}{ Konsumsi Buah dan Sayur } & \multirow{2}{*}{\multicolumn{2}{|c|}{ Total }} & \multirow{3}{*}{ p value } \\
\hline & \multicolumn{2}{|c|}{ Kurang } & \multicolumn{2}{|c|}{ Baik } & & & \\
\hline & $\mathbf{n}$ & $\%$ & $\mathbf{n}$ & $\%$ & $\mathbf{n}$ & $\%$ & \\
\hline \multicolumn{8}{|l|}{ Sikap } \\
\hline 1. Kurang baik & 25 & 89,3 & 3 & 10,7 & 28 & 100 & 0,0005 \\
\hline 2. Baik & 13 & 40,6 & 19 & 59,4 & 32 & 100 & \\
\hline \multicolumn{8}{|l|}{ Pengetahuan } \\
\hline 1. Kurang baik & 26 & 83,9 & 5 & 16,1 & 31 & 100 & 0,001 \\
\hline 2. Baik & 12 & 41,4 & 17 & 58,6 & 29 & 100 & \\
\hline \multicolumn{8}{|l|}{ Ketersediaan Buah dan Sayur di } \\
\hline Rumah & 17 & 81,0 & 4 & 19,0 & 21 & 100 & 0,038 \\
\hline $\begin{array}{l}\text { 1. Kurang baik } \\
\text { 2. Baik }\end{array}$ & 21 & 53,8 & 18 & 46,2 & 39 & 100 & \\
\hline
\end{tabular}

Pengetahuan siswa yang kurang baik terhadap konsumsi buah dan sayur kurang sebesar 83,9\%. Hasil uji statistik menunjukkan bahwa ada hubungan yang signifikan antara pengetahuan dengan konsumsi buah dan sayur ( $\mathrm{p}$ $=0,001)$. Ketersediaan buah dan sayur di rumah yang kurang baik menyebabkan konsumsi buah dan sayur siswa kurang yaitu sebanyak 17 orang
$(81,1 \%)$. Sedangkan ketersediaan buah dan sayur di rumah baik menyebabkan konsumsi buah dan sayur kurang sebanyak 21 orang $(53,8 \%)$. Hasil uji statistik menunjukkan bahwa ada hubungan yang signifikan antara ketersediaan buah dan sayur di rumah dengan konsumsi buah dan sayur siswa $(\mathrm{p}=0,038)$.

Tabel 4 Hubungan antara Konsumsi Buah dan Sayur dengan Status Gizi Siswa SMA

Xaverius 2 Palembang

\begin{tabular}{|c|c|c|c|c|c|c|c|}
\hline \multirow{3}{*}{$\begin{array}{l}\text { Konsumsi Buah dan } \\
\text { Sayur }\end{array}$} & \multicolumn{4}{|c|}{ Indeks Masa Tubuh } & \multirow{2}{*}{\multicolumn{2}{|c|}{ Total }} & \multirow{3}{*}{$\begin{array}{c}p \\
\text { value }\end{array}$} \\
\hline & \multicolumn{2}{|c|}{ Kurang } & \multicolumn{2}{|c|}{ Normal } & & & \\
\hline & $\mathrm{n}$ & $\%$ & $\mathrm{n}$ & $\%$ & $\mathrm{n}$ & $\%$ & \\
\hline 1. Kurang & 14 & 36,8 & 24 & 63,2 & 38 & 100 & 0,005 \\
\hline 2. Baik & 1 & 4,5 & 21 & 95,5 & 22 & 100 & \\
\hline Total & 15 & 25.0 & 22 & 75.0 & 60 & 100 & \\
\hline
\end{tabular}

Tabel 4 menunjukkan bahwa konsumsi buah dan sayur yang kurang dengan status gizi yang obesitas sebesar $(36,8 \%)$ dan kategori baik sebesar $4,5 \%$. Hasil uji statistik di didapatkan

\section{PEMBAHASAN}

Sebagian besar siswa SMA 2 Xaverius Palembang konsumsi buah dan sayurnya kurang yaitu sebanyak 38 orang $(63,3 \%)$ sedangkan yang konsumsi buah dan sayur yang baik sebanyak 22 orang $(36,7 \%)$. Hasil penelitian ini sejalan dengan penelitian yang dilakukan di Pekan Baru menyatakan bahwa tingkat konsumsi buah dan sayur pada siswa SMA Negeri 1 Pekan Baru masih kurang dari angka yang dianjurkan. ${ }^{11}$ Begitu juga dengan penelitian yang dilakukan di Jakarta Barat yang menyatakan bahwa konsumsi buah dan sayur pada remaja termasuk rendah, hal $p$ value $=0,0005$ yang menunjukkan bahwa ada hubungan yang signifikan antara konsumsi buah dan sayur dengan status gizi.

ini dikarenakan bahwa buah dan sayur bukan merupakan makanan prestige dibandingkan makanan fast food yang sedang tren di kalangan remaja saat ini. Sehingga hal tersebut berdampak pada konsumsi buah dan sayur remaja berkurang. ${ }^{12}$

Sikap siswa yang kurang baik dan konsumsi buah dan sayur yang kurang sebesar $89,3 \%$. Hasil uji statistik menunjukkan bahwa ada hubungan yang signifikan antara sikap dengan konsumsi buah dan sayur $(p=0,0005)$. Sikap merupakan suatu reaksi atau respon 
seseorang terhadap suatu stimulus atau objek. ${ }^{13}$ Menurut penelitian yang dilakukan pada masyarakat di Lampung menunjukkan bahwa umumnya masyarakat mengetahui pentingnya konsumsi sayuran dan buah untuk kesehatan, tetapi pemahaman yang mendalam masih sangat kurang sehingga tidak menjadi dasar timbulnya motivasi yang kuat untuk mengonsumsi sayuran dan buah. ${ }^{14}$

Pengetahuan siswa yang kurang baik terhadap konsumsi buah dan sayur kurang sebesar $83,9 \%$. Hasil uji statistik menunjukkan bahwa ada hubungan yang signifikan antara pengetahuan dengan konsumsi buah dan sayur ( $p$ $=0,001)$. Hasil penelitian ini sejalan dengan penelitian yang dilakukan di asrama UI, yang menyatakan bahwa pengetahuan berhubungan dengan konsumsi buah dan sayur pada mahasiswa di asrama UI. ${ }^{15}$ Penelitian pada SMU 1 Bogor dan SMU Pamekasan juga menyebutkan bahwa ada hubungan yang bermakna antara konsumsi sayuran dengan pengetahuan gizi siswa. ${ }^{16}$

Ketersediaan buah dan sayur di rumah yang kurang baik menyebabkan konsumsi buah dan sayur siswa kurang yaitu sebanyak 17 orang $(81,1 \%)$. Sedangkan ketersediaan buah dan sayur di rumah baik menyebabkan konsumsi buah dan sayur kurang sebanyak 21 orang $(53,8 \%)$. Hasil uji statistik menunjukkan bahwa ada hubungan yang signifikan antara ketersediaan buah dan sayur di rumah dengan konsumsi buah dan sayur siswa $(p=0,038)$. Hasil penelitian ini sejalan dengan penelitian di Sumatera Utara yang menyatakan bahwa ada hubungan yang bermakna antara ketersediaan di rumah dengan perilaku makan sayur pada anak. ${ }^{17}$ Ketersediaan buah dan sayur di rumah berhubungan dengan konsumsi buah dan sayur pada remaja. ${ }^{18,19}$ Penelitian yang dilakukan di Surabaya pada anak pra sekolah

\section{KESIMPULAN DAN SARAN}

Konsumsi buah dan sayur pada siswa SMA Xaverius 2 Palembang sebagian besar masih kurang, ini dipengaruhi oleh sikap, pengetahuan dan ketersediaan buah dan sayur di rumah dengan konsumsi buah dan sayur siswa SMA Xaverius 2 Palembang. Konsumsi buah dan sayur mempengaruhi status gizi siswa SMA Xaverius 2

\section{UCAPAN TERIMA KASIH}

Penulis mengucapkan terima kasih kepada pihak-pihak yang telah membantu dalam menunjukkan bahwa terdapat hubungan yang bermakna antara ketersediaan sayur di rumah dengan konsumsi sayur. ${ }^{20}$ Jenis makanan yang tersedia akan lebih banyak memberikan peluang untuk dikonsumsi. Jadi upaya untuk menyediakan lebih banyak buah dan sayur di rumah dapat meningkatkan konsumsi buah dan sayur. ${ }^{21}$

Tabel 5 menunjukkan bahwa konsumsi buah dan sayur yang kurang dengan status gizi yang obesitas sebesar $(36,8 \%)$ dan kategori baik sebesar 4,5\%. Hasil uji statistik di didapatkan $p$-value $=0,0005 \quad(\alpha<0,05)$ yang menunjukkan bahwa ada hubungan yang signifikan antara konsumsi buah dan sayur dengan status gizi. Hasil penelitian ini sejalan dengan penelitian yang dilakukan di Kota Yogyakarta dan Kabupaten Bantul yang menyatakan bahwa ada hubungan yang signifikan antara asupan sayuran dengan kegemukan. ${ }^{22}$ Sedangkan hasil penelitian yang dilakukan di Makasar dan Tasikmalaya menyatakan bahwa tidak ada hubungan yang signifikan antara konsumsi buah dan sayur dengan kejadian obesitas. ${ }^{22,24}$

Faktor risiko utama yang menyebabkan obesitas adalah faktor perilaku yaitu pola makan yang tidak sehat ditambah dengan konsumsi serat yang berasal dari buah dan sayur tidak mencukupi serta aktivitas fisik yang rendah. ${ }^{25}$

Asupan makanan berbasis tanaman (plant foods) spesifik secara rutin dapat mencegah overweight pada anak-anak dan remaja, karena diet berbasis tanaman (plant foods) ini rendah densitas energinya dan tinggi karbohidrat kompleks, serat, dan air, sehingga dapat meningkatkan rasa kekenyangan dan dapat berefek pengurangan asupan makanan lain (makan besar) sehingga dapat mengontrol berat badan. ${ }^{26}$

Palembang.

Bagi pihak sekolah dan pemerintah khususnya Dinas Kesehatan diharapkan agar dapat melakukan sosialisasi tentang pentingnya konsumsi buah dan sayur pada siswa SMA Xaverius 2 Palembang

pelaksanaan penelitian ini. 


\section{DAFTAR PUSTAKA}

1. Kementrian Kesehatan. 2013. Riset Kesehatan Dasar 2013. Jakarta (ID): Badan Penelitian Pengembangan Kesehatan Kementerian Kesehatan RI.

2. Dauchet L, Amouyel P, Hercberg S, Dallongeville J. 2006. Fruit and vegetable consumption and risk of coronary heart disease: a meta-analysis of cohort studies. The Journal of Nutrition. 136(10): 2588.

3. Pollard CM. 2008. Determinants of fruit and vegetables consumption among adults in Perth, Western Australia [disertasi]. Perth (AU): Curtin University of Technology.

4. Patrick H, Theresa A, Nicklas. 2005. A review of family and social determinants of children's eating patterns and diet quality. Journal of the American College of Nutrition. 24(2):83-92.

5. Jago R, Baranowski T, Baranowski JC. 2007. Fruit and vegetable availability: a micro environmental mediating variable? Public Health Nutrition. 10(7): 681-689.doi: 10.1017/S1368980007441441.

6. Jago R, Baranowski T, Baranowski JC. 2007. Fruit and vegetable availability: a micro environmental mediating variable? Public Health Nutrition. 10(7): 681-689.doi: 10.1017/S1368980007441441.

7. Scaglioni S, Arrizza C, Vecchi F, Tedeschi S. 2011. Determinants of children's eating behavior. Am J Clin Nutr. 94(suppl):2006S$11 \mathrm{~S}$.

8. Hausner H, Olsen A, Møller P. 2012. Mere exposure and flavour-flavour learning increase 2-3 year-old children's acceptance of a novel vegetable. Appetite. 58:11521159.

9. Kementrian Kesehatan. 2013. Riset Kesehatan Dasar 2013. Jakarta (ID): Badan Penelitian Pengembangan Kesehatan Kementerian Kesehatan RI.

10.Bahria dan Triyanti. 2010.Hubungan antara Pemgetahuan Gizi, Kesukaan dan Faktor Lain dengan Konsumsi Buah dan Sayur pada Remaja di 4 SMAdi Jakarta Barat. Skripsi Program Sarjana Kesehatan Masyarakat FKM UI. Jakarta (ID). Depok: FKM UI.

11.Gustiara I. 2013. Konsumsi Sayur dan Buah pada Siswa SMA Negeri 1 Pekanbaru. Jurnal Precure, 1. Epi Treat Unit-Universitas Sumatera Utara.
12.Bahria dan Triyanti. 2010.Hubungan antara Pemgetahuan Gizi, Kesukaan dan Faktor Lain dengan Konsumsi Buah dan Sayur pada Remaja di 4 SMAdi Jakarta Barat. Skripsi Program Sarjana Kesehatan Masyarakat FKM UI. Jakarta (ID). Depok: FKM UI.

13. Notoatmodjo S. 2003. Pendidikan dan Perilaku Kesehatan. Jakarta (ID): PT Rineka Cipta.

14.Aswatini, Mita N , Fitranita. 2008. Konsumsi Sayur dan Buah di Masyarakat dalam Konteks Pemenuhan Gizi Seimbang. Pusat Penelitian Kependudukan Lembaga Ilmu Pengetahuan Indonesia (PPK-LIPI), 3(2).

15.Gusti S. 2004. Gambaran Konsumsi Sayuran pada Penghuni Asrama Mahasiswa Universitas Indonesia Tahun 2002. Skripsi Program Sarjana Kesehatan Masyarakat. Depok: FKM UI.

16. Setyowati, 2000. Konsumsi dan Preferensi Sayur dan Buah pada Remaja di SMU I Bogor dan SMU I Pamekasan. Skripsi. Bogor: Fakultas Pertanian IPB.

17.Rahmawi. 2006. Harga Diri pada Remaja Obesitas.http://Library.USU.Ac.Ac.Id/Downl oad/Fk/ 06009832.Pdf.

18. Young, Elizabeth M, Fors, Stuart W, Hayes, David M. 2004. Associations between Perceived Parent Behaviors and Middle School Student Fruits and Vegetable Consumption. Journal of Nutrition Education and Behavior. 36: 2-12.

19.Cullen KW. et al, 2001. Child Reported Family and Peer Influences on Fruit, Juice and Vegetable Comsumpstion: Reliabilty and Validity of Measures. Health Education Research. 16 (2): 187-200.

20.Gunanti I, 2000. Faktor-Faktor Yang Mempengaruhi Konsumsi Sayuran Pada Anak Pra-Sekolah. Skripsi. Universitas Airlangga, Surabaya (ID)

21.Reynols KD, Knut-Inge Klepp, Amy LY. 2004. Strategi Gizi Kesehatan Masyarakat untuk Intervensi di Tingkat Ekologis. Di dalam Michael J. Gibney. Gizi Kesehatan Masyarakat. Jakarta (ID) : EGC

22.Nureani dkk. 2016. Perbedaan konsumsi buah dan sayur pada anak sekolah dasar yang obes dan tidak obes di Kota Yogyakarta dan Kabupaten Bantul. ejournal. almaata.ac.id/index.php/IJND/article/downlo $\mathrm{ad} / 43 / 42$ 
(JPP) Jurnal Kesehatan Poltekkes Palembang

Vol. 14, No. 1, Juni 2019, eISSN 2654-3427

23. Aflah dkk. 2013. Hubungan Pola Makan dengan Kejadian Obesitas pada Remaja SMA Katolik

Candrawasih.

http://repository.unhas.ac.id/bitstream/handle/ 123456789/10878/RIZKA\%20RUHUL\%20A FLAH\%20K21110105.pdf?sequence $=1$

24. Nugraha. 2013. Perbedaan Konsumsi Sayur Dan Buah Berdasarkan Status Kegemukan Pada Siswa SMA (Survei Pada Siswa Kelas Xi Sman 8 Kecamatan Tamansari Kota
Tasikmalaya).

https $: / /$ journal.unsil.ac.id/download.php?id=5719

25.Sartika RAD. 2011. Faktor risiko obesitas pada anak 5-15 tahun di Indonesia. Makara Kesehatan. 15(1): 37-43.

26. Hu FB. 2003., Plant-based foods and prevention of cardiovascular disease: an overview. Am J Clin Nutr. 78(suppl): 544S$51 \mathrm{~S}$. 